\section{Expression of the endocannabinoid receptors in human fascial tissue}

\author{
C. Fede, ${ }^{1}$ G. Albertin, ${ }^{1}$ L. Petrelli, ${ }^{1}$ \\ M.M. Sfriso, ${ }^{1}$ C. Biz, ${ }^{2}$ R. De Caro, ${ }^{1}$ \\ C. Stecco ${ }^{1}$
}

'Department of Molecular Medicine, University of Padua

'Department of Surgery, Oncology and Gastroenterology, Orthopedic Clinic, University of Padua, Italy

\section{Abstract}

Cannabinoid receptors have been localized in the central and peripheral nervous system as well as on cells of the immune system, but recent studies on animal tissue gave evidence for the presence of cannabinoid receptors in different types of tissues. Their presence was supposed also in myofascial tissue, suggesting that the endocannabinoid system may help resolve myofascial trigger points and relieve symptoms of fibromyalgia. However, until now the expression of $\mathrm{CB} 1$ (cannabinoid receptor 1) and CB2 (cannabinoid receptor 2) in fasciae has not yet been established. Small samples of fascia were collected from volunteers patients during orthopedic surgery. For each sample were done a cell isolation, immunohistochemical investigation (CB1 and CB2 antibodies) and real time RT-PCR to detect the expression of CB1 and CB2. Both cannabinoid receptors are expressed in human fascia and in human fascial fibroblasts culture cells, although to a lesser extent than the control gene. We can assume that the expression of mRNA and protein of $\mathrm{CB} 1$ and $\mathrm{CB} 2$ receptors in fascial tissue are concentrated into the fibroblasts. This is the first demonstration that the fibroblasts of the muscular fasciae express CB1 and CB2. The presence of these receptors could help to provide a description of cannabinoid receptors distribution and to better explain the role of fasciae as pain generator and the efficacy of some fascial treatments. Indeed the endocannabinoid receptors of fascial fibroblasts can contribute to modulate the fascial fibrosis and inflammation.

\section{Introduction}

The deep fascia is the dense connective layer that surround muscles, bones, nerves and blood vessels. In recent time it have gained importance in the clinical practice for its role in motor coordination, proprioception, balance and myofascial pain. ${ }^{1}$ The deep fascia contains variable amount of fibroblasts soaked in extracellular matrix and many Authors support their possible role in fascial pathology. Schleip et al. ${ }^{2}$ highlighted the presence of alpha SMA fibers in the fibroblasts of the muscular fascia; Goldman et al. ${ }^{3}$ demonstrated that purine signaling induces transient changes in fibroblast cytoarchitecture, whilst McPartland et al. ${ }^{4}$ suggest a possible influence of the endocannabinoid system. Endocannabinoids are endogenous lipid mediators with wide range of biological effects similar to those of marijuana. These lipid mediators can be generated in various cell types, both in the brain as well as in various peripheral tissues.-7

Endocannabinoids exert their biological effects via two main G-protein-coupled cannabinoid receptors, the CB1 and CB2., ${ }^{8,9}$ $\mathrm{CB} 1$ receptors are primarily distributed in the central nervous system, however, recent studies have also demonstrated CB1 receptors in various peripheral tissues. ${ }^{10}$ The presence of CB2 receptors has also been established in the myocardium, ${ }^{7}$ human coronary endothelial and smooth muscle cells, ${ }^{11,12}$ brain, ${ }^{13}$ and the liver ${ }^{14,15}$ and in human peripheral blood immune cells. ${ }^{16}$ More recently, patients with myofascial pain and arthritis are those most often use cannabis medicinally so probably the activation of $\mathrm{CB} 1$ and 2 receptors suppresses proinflammatory cytokines such as IL-1beta e TNF-alpha and increases antiinflammatory cytokines. ${ }^{17}$ Garcia-Gonzalez et $a l .{ }^{18}$ demonstrated that the endocannabinoid system is up-regulated in pathologic fibrosis and that modulation of the cannabinoid receptors might limit the progression of uncontrolled fibrogenesis. Pandey et al. ${ }^{19}$ review the role of endocannabinoids in the regulation of the immune response and the potential to treat inflammatory disorders, and Lowin et al. ${ }^{20}$ demonstrated that synovial fibroblasts can contribute significantly to elevated endocannabinoid levels in rheumatoid arthritis synovial fluid. Russo ${ }^{21}$ has shown a link to fibromyalgia and endocannabinoid deficiency and some studies provide data that cannabinoids can prove to be an effective treatment of fibromyalgia symptoms. ${ }^{22}$

Really, up to now the expression of cannabinoid receptors $\mathrm{CB} 1$ and $\mathrm{CB} 2$ in fascial fibroblasts was never demonstrated, even though many evidences support their influence in fascial pathology. The aim of this study was to evaluate the gene and protein expression of $\mathrm{CB} 1$ and $\mathrm{CB} 2$ receptors on human fascia lata and isolated fibroblasts of hip deep fascia.
Correspondence: Prof. Carla Stecco, Section of Anatomy, Department of Molecular Medicine, University of Padua, via A. Gabelli 65, 35121 Padova, Italy.

Tel. +39.049 .8272315 - Fax: +39.049 .8272328 .

E-mail: carla.stecco@unipd.it

Conflict of interest: the authors declare no conflict of interest.

Key words: fascia; fascial fibroblasts; endocannabinoid; immunostaining.

Contributions: CF, manuscript writing, isolation, culture cells, RT-PCR; GA, contribution to manuscript writing and PCR execution; LP, immunostaining; MMS, contribution to cells isolation and immunostaining; $\mathrm{CB}$, collection of fascia from volunteers patients; RDC, CS, contribution to manuscript writing and editing, study coordination. All authors contributed to this work and approved the final version of the paper.

Received for publication: 24 March 2016. Accepted for publication: 1 June 2016.

This work is licensed under a Creative Commons Attribution-NonCommercial 4.0 International License (CC BY-NC 4.0).

(C) Copyright C. Fede et al., 2016

Licensee PAGEPress, Italy

European Journal of Histochemistry 2016; 60:2643 doi:10.4081/ejh.2016.2643

\section{Materials and Methods}

\section{Cell isolation from fascia}

This study was approved by the Institutional Ethical Review Board (approval no. 3722/A0/16). The Institute's ethical regulations on research conducted on human tissues were followed, and written informed consent was obtained from each donor. A few millimeters large samples of fascia lata, the deep fascia of the thigh, were collected from 11 volunteers patients, 4 males and 7 females, average age $84 \pm 13$ (range 50-97), undergoing an elective surgical procedure at the Orthopedic Clinic of University of Padua. The samples were transferred into phosphate buffered saline (PBS) containing $1 \%$ penicillin and streptomycin, and transported to the laboratory within few hours of collection. Fascia was digested with Collagenase B 0.1\% in HBSS (Hank's Balanced Salt Solution) overnight, then centrifuged at $480 \mathrm{~g}$ for $5 \mathrm{~min}$ and transferred in tissue flask with DMEM 1g/L glucose, 10\% FBS and 1\% penicillin-streptomycin antibiotic. Cell culture was incubated at $37^{\circ} \mathrm{C}, 95 \%$ humidity and $5 \% \mathrm{CO}_{2}$, and used from passage $3^{\text {rd }}$ to $9^{\text {th }}$. 


\section{Immunocytochemistry and immunohistochemistry}

Formalin fixed specimens of human fascia were dehydrated in graded ethanol, embedded in paraffin and cut into $6 \mu \mathrm{m}$-thick sections. For the detection of CB1 and CB2 Receptor, dewaxed sections were treated with Tris-EDTA pH 9.0 buffer, for $15 \mathrm{~min}$ at $90^{\circ} \mathrm{C}$, rinsed by water and then washed in PBS.

Isolated cells from fascia were plated (200 cells $/ \mathrm{mm}^{2}$ in 24 -multiwells containing a glass coverslip) and allowed to attach for $48 \mathrm{~h}$ at $37^{\circ} \mathrm{C}$. Then cells were washed in PBS, fixed 10 min with $2 \%$ paraformaldehyde in PBS pH 7.4 and then washed three times in PBS. Afterwards, all the samples (tissues and cells) followed the protocol described below.

Endogen peroxidase were blocked with $0.5 \%$ $\mathrm{H}_{2} \mathrm{O}_{2}$ in PBS for $10 \mathrm{~min}$ at room temperature. Cells were pre-incubated with a permeabilizing buffer (0.2\% Tween-20 in PBS) for $60 \mathrm{~min}$ at room temperature and then were incubated in rabbit polyclonal antibodies diluted 1:50 for anti-CB1 Receptor (Cayman Chemical, Ann Arbor, MI, USA), 1:100 for anti-CB2 Receptor rabbit polyclonal antibodies (Cayman Chemical) and 1:100 for anti-Fibroblast Surface Protein[1B10] Mouse monoclonal antibodies (AbCam, Cambridge, UK). The primary antibodies were diluted in the same preincubation buffer and incubated overnight at $4^{\circ} \mathrm{C}$. After repeated PBS washing, cells were incubated with the secondary antibody Advance HRP Detection System (Dako, Carpinteria, CA, USA), ready to use, for mouse and rabbit, and washed in PBS buffer. The reaction was then developed with 3,3 'diaminobenzidine (Liquid DAB + substrate Chromogen System kit; Dako) and stopped with distilled water. Negative controls were carried out by similarly treating sections and omitting the primary antibody, confirming the specificity of the immunostaining. Spleen sample for CB2 receptors and hippocampus for CB1 were used as positive control. Nuclei in tissue sections were counterstained with hematoxylin, ready to use (Dako). The images were acquired by using Leica DMR microscope (Leica Microsystems, Wetzlar, Germany; objectives 20X and 40X, Leica) and analyzed using the Image $\mathbf{J}$ software.

\section{Real-time PCR}

To detect the expression of mRNA for CB1 and CB2, and the changes it underwent in the different samples of fascia, cells isolated from human fascia from the $3^{\text {rd }}$ passage were seeded $\left(3 \times 10^{4}\right.$ cells/well) on a 24 -well plate. After $48 \mathrm{~h}$ incubation with medium, the cells were harvested in RNA lysis buffer and total RNA was extracted with the SV Total RNA Isolation System (Promega Corporation, Madison, WI, USA) and purified. Tissue speci- mens were homogenized in RNA lysis buffer, and total RNA was extracted with the same protocol used for cells.

During RNA extraction a DNAse treatment was also carried out to remove genomic DNA contamination. Total RNA was then transcribed to $\mathrm{cDNA}^{23}$. RT-PCR was carried out in an I-Cycler iQ detection system (BioRad Laboratories, Milan, Italy), as detailed previously, ${ }^{24}$ using the primers reported in Table 1, and a $60 \mathrm{ng}$ starting amount of cDNA. The PCR program included a denaturation step at $95^{\circ} \mathrm{C}$ for $3 \mathrm{~min}, 45$ cycles of three amplification steps $\left(15 \mathrm{~s} 95^{\circ} \mathrm{C}-15 \mathrm{~s} 60^{\circ} \mathrm{C}-15 \mathrm{~s} 72^{\circ} \mathrm{C}\right)$ and melting curve $\left(60-90^{\circ} \mathrm{C}\right.$ with a heating rate of $0.5^{\circ} \mathrm{C} / 10 \mathrm{~s}$ ). During the exponential phase, the fluorescence signal threshold was calculated and the fraction number of PCR cycles required to reach the threshold (cycle threshold, Ct) was determined. Ct values decreased linearly with increasing input target quantity. All samples were amplified in duplicate and RPS18 (Ribosomal Protein S18) expres-
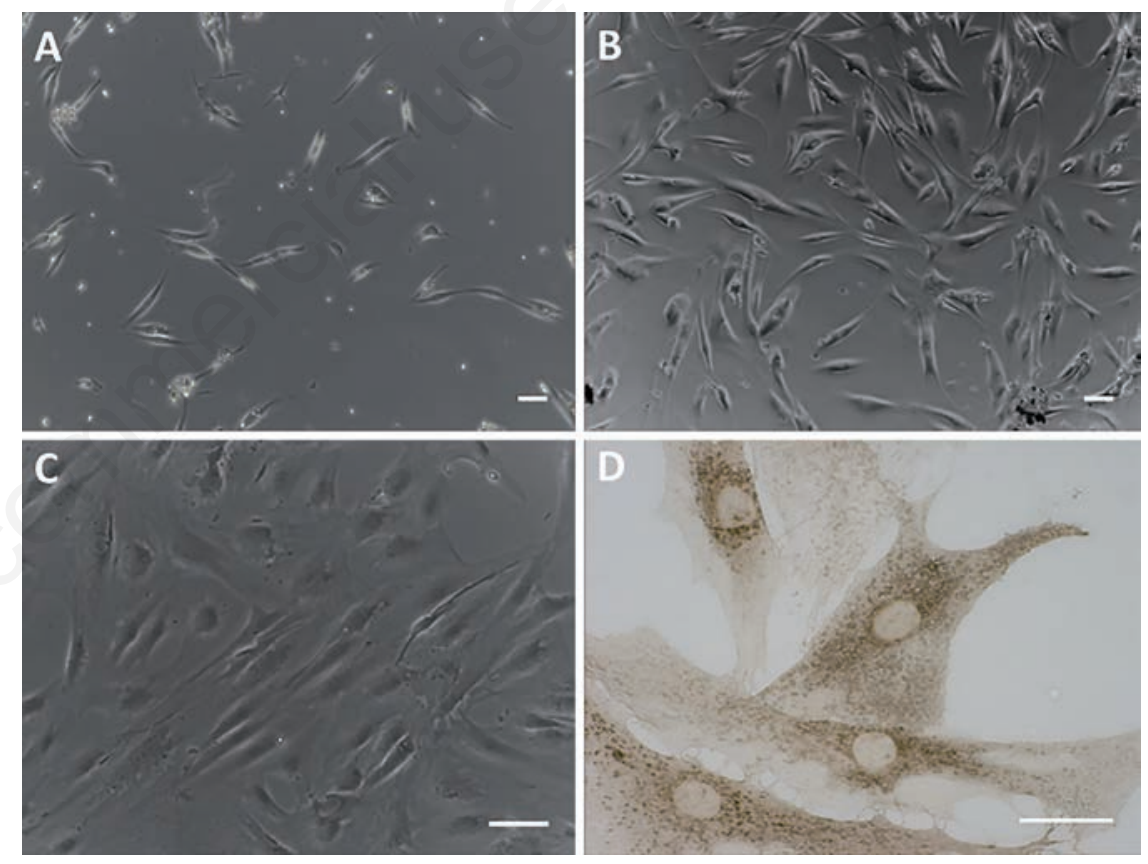

Figure 1. Fibroblasts derived from human hip fascia after digestion with Collagenase $B$ : after 5 days from isolation (A), $1^{\text {st }}$ passage (B), and $7^{\text {th }}$ passage $(C)$. Scale bars: $100 \mu \mathrm{m}$. D) Immunocytochemical assay on isolated cells ( $7^{\text {th }}$ passage) with anti-fibroblast surface protein antibody (Abcam, 1:100). Scale bar: $50 \mu \mathrm{m}$.

Table 1. Sense and antisense sequences used as RT-PCR primers.

\begin{tabular}{lccl} 
Sequence name & Acc. number & BP & Primers \\
RPS18 F171 & NM_022551 & \multirow{2}{*}{170} & 5'-TGT GGT GTT GAG GAA AGC AG-3' \\
RPS18 R340 & & & 5'-GGA CCT GGC TGT ATT TTC CA-3' \\
CB1 F4961 & NM_001160226 & 363 & 5'-CCT TTT GCT GCC TAA ATC CAC-3' \\
CB1 R5323 & & & 5'-CCA CTG CTC AAA CAT CTG AC-3' \\
CB2 F1008 & NM_001841 & 353 & 5'-TCA ACC CTG TCA TCT ATG CTC-3' \\
CB2 R1360 & & & 5'-AGT CAG TCC CAA CAC TCA TC-3' \\
\hline
\end{tabular}


days (Figure 1B). Figure 1C shows that, after few passages, the primary cultured cells are longitudinally oriented. The immunoistochemical staining using the anti-fibroblast surface protein antibody demonstrated that the isolated cells are fibroblasts (Figure 1D).

Our protocol of immunostaining allowed to maintain the integrity of fascial tissue: Figure $2 \mathrm{C}-\mathrm{J}$ shows the fascial organization, with longitudinal orientation of collagen fibers and elongated fibroblasts. Figure 2 demonstrates the positive expression of CB1 (panels E,G,I) and CB2 (panels F,H,J) on the most of fascial fibroblasts. Not all the cells have the same degree of reactivity, but in all the samples the positivity for $\mathrm{CB} 1$ and $\mathrm{CB} 2$ is evident in the cytoplasm of cells, whereas the nuclei are all negative. Positive tissue controls are shown in Figure $2 \mathrm{~A}, \mathrm{~B}$ as indicated in the data sheet of the antibodies. These results are also confirmed in the cells isolated from patients (Figure 3): all the cells are positive in the cytoplasmic area and not in the nucleus, with a slightly higher intensity for CB2 (Figure 3 $\mathrm{B}, \mathrm{D})$ compared to $\mathrm{CB} 1$ (Figure $3 \mathrm{~A}, \mathrm{C}$ ).

With the aim to confirm the expression of the endocannabinoid receptors, we carried out a RT-PCR in cells and tissue samples with the same amount of starting cDNA. The results confirm that $\mathrm{CB} 1$ and $\mathrm{CB} 2$ are both expressed on fibroblasts and hip fascial tissue (Table 2), although with a lower $\mathrm{Ct}$ compared to the housekeeping gene S18, and with a slightly higher expression of CB2 with respect to CB1, as indicated by the lower $\mathrm{Ct}$. The variability of expression of the housekeeping gene between cells and fascial tissue (15.7 \pm 0.4 and $18.6 \pm 0.3$, respectively) can be justified by the different starting material (isolated cells and pools of cells, respectively), as indicated by the literature. ${ }^{26}$ Figure 4 shows that all samples have the same melting temperature, demonstrating the specificity of the reaction and excluding false amplicons. Furthermore, even in this case, the fascial tissue points out a lower expression (as indicated by the real time PCR plots): these results could suggest that the expression of CB1 and CB2 derive from the average expression of a pool of cells, namely a low number of fibroblasts and a variable presence of different type of cells such as vascular cells, mast cells and adipocytes that are present on the tissue and that could have a different expression of endocannabinoid receptors.

\section{Discussion}

This is the first demonstration of the presence of endocannabinoid receptors in fascial fibroblasts. More in detail, our immunostaining results demonstrate a slightly higher
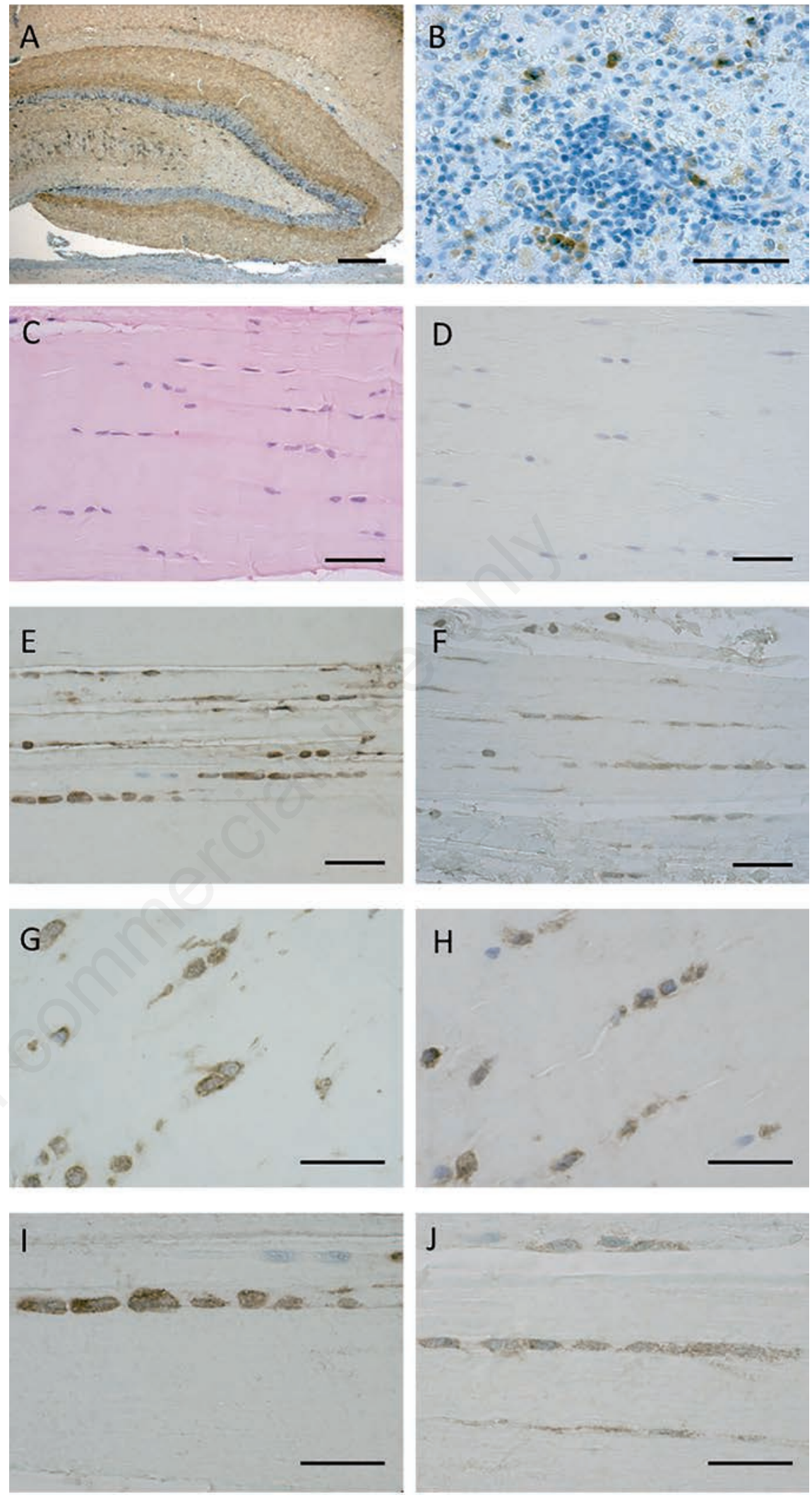

Figure 2. $\mathrm{CB} 1$ and $\mathrm{CB} 2$ receptor expression in positive controls and human fascia. The positivity for CB1 is evident in dentate gyrus of the rat hippocampus (A), whereas CB2receptor-positive cells of immune system are shown in human spleen (B). Paraffin sections of the human fascia stained with $H \& E(C)$, immunostaining negative controls Hematoxylin stained (D), CB1 receptor expression in human fascia of two different subjects $(E, G, I), C B 2$ receptor in other two subjects $(F, H, J)$. Scale bars: $50 \mu \mathrm{m}$. 
intensity for $\mathrm{CB} 2$ compared to $\mathrm{CB} 1$ on fascial fibroblasts. Besides, in the tissue not all the fibroblasts are positive, whereas the isolated and expanded cells are homogeneous. These results are confirmed by the real time PCR: the specificity of the reaction on fibroblasts and fascial tissue is the same, but the amount of expression in the tissue is lower, for both CB1 and CB2 and also for the housekeeping gene. This can be explained by the fact that the cell culture is homogeneous, while the tissue is a pool of different cells (fibroblasts, vascular cells, mast cells, adipocytes, etc.) with a variability of expression.

The presence of $\mathrm{CB} 1$ and $\mathrm{CB} 2$ receptors in fascial fibroblasts suggests their possible role in modulation of fascial pain. The fascial pain is usually related to a fascial inflammation and/or a fascial fibrosis, ${ }^{1}$ and both could be related to an alteration to the endocannabinoid system. Indeed the activation of CB1 and CB2 receptors is able to suppress pro-inflammatory cytokines such as IL-1beta e TNF-alpha and to increase anti-inflammatory cytokines, ${ }^{17}$ and provide an anti-fibrotic activity. ${ }^{18}$ Consequently, the $\mathrm{CB} 1$ and $\mathrm{CB} 2$ receptors of fascial fibroblasts could represent a new target for drugs to care fascial fibrosis and inflammation. The presence of the endocannabinoid system in the fascial fibroblasts can also explain the efficacy of cannabis to care myofascial pain. ${ }^{27}$

It is also possible that the endocannabinoid system inside the deep fasciae is stimulated during manipulative treatments and exercises. Indeed, McPartland et al. ${ }^{4}$ demonstrated that after osteopathic manipulation treatment the serum level of anandamide increase $168 \%$ over pretreatment levels and Gamelin et al. ${ }^{28}$ demonstrated that chronic exercise is able to modify the tissue levels of endocannabinoids
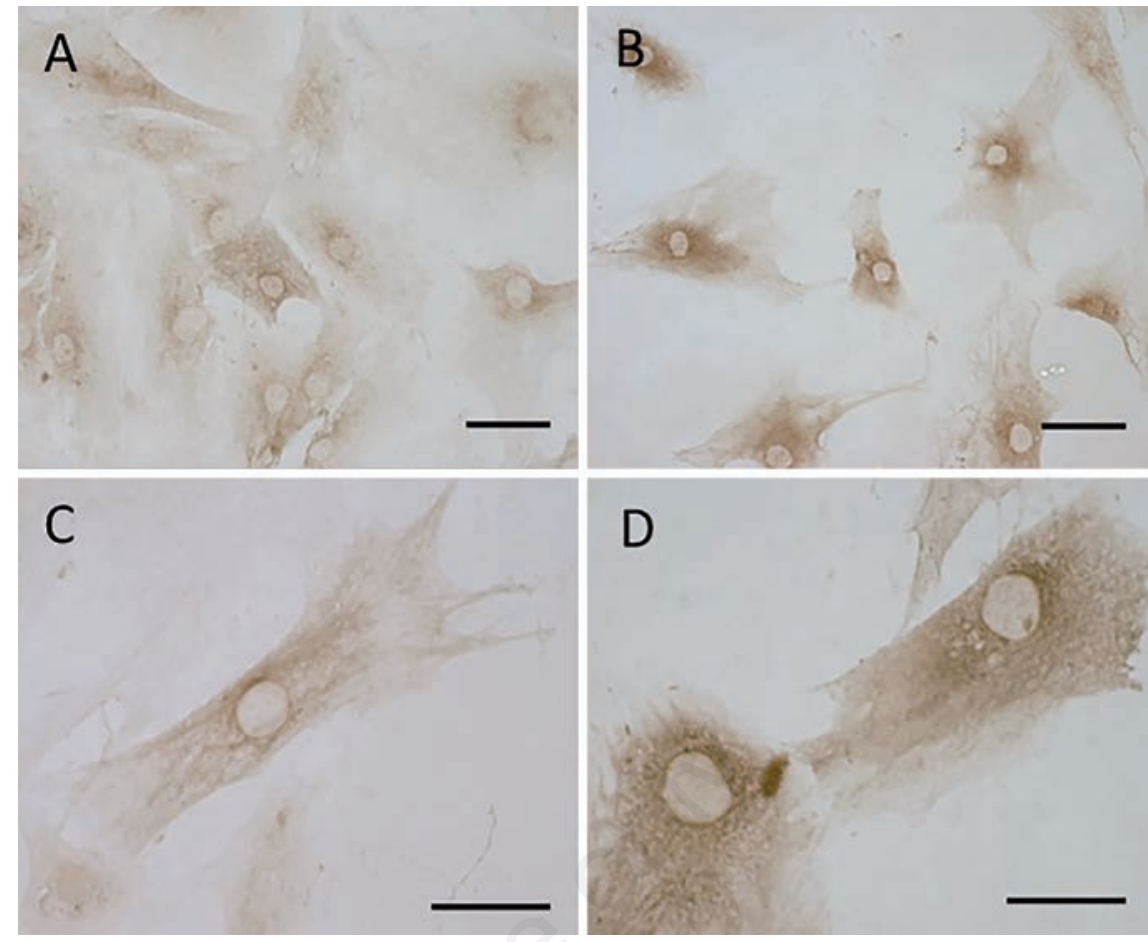

Figure 3. $\mathrm{CB} 1$ and $\mathrm{CB} 2$ receptor gene expression in human fascial fibroblasts: $\mathrm{CB} 1(\mathrm{~A}, \mathrm{C})$ and CB2 (B,D). Scale bars: $50 \mu \mathrm{m}$.

Table 2. Comparison of Ct for real time PCR. The values are the mean of at least two different experiments in triplicate.

\begin{tabular}{lcc} 
& Ct (filbroblast cells) & Ct (fascial tissue) \\
CB1 & $29.5 \pm 0.7$ & $29.6 \pm 1.4$ \\
CB2 & $28.9 \pm 0.7$ & $28.3 \pm 1.5$ \\
\hline S18 & $15.7 \pm 0.4$ & $18.6 \pm 0.3$ \\
\hline
\end{tabular}
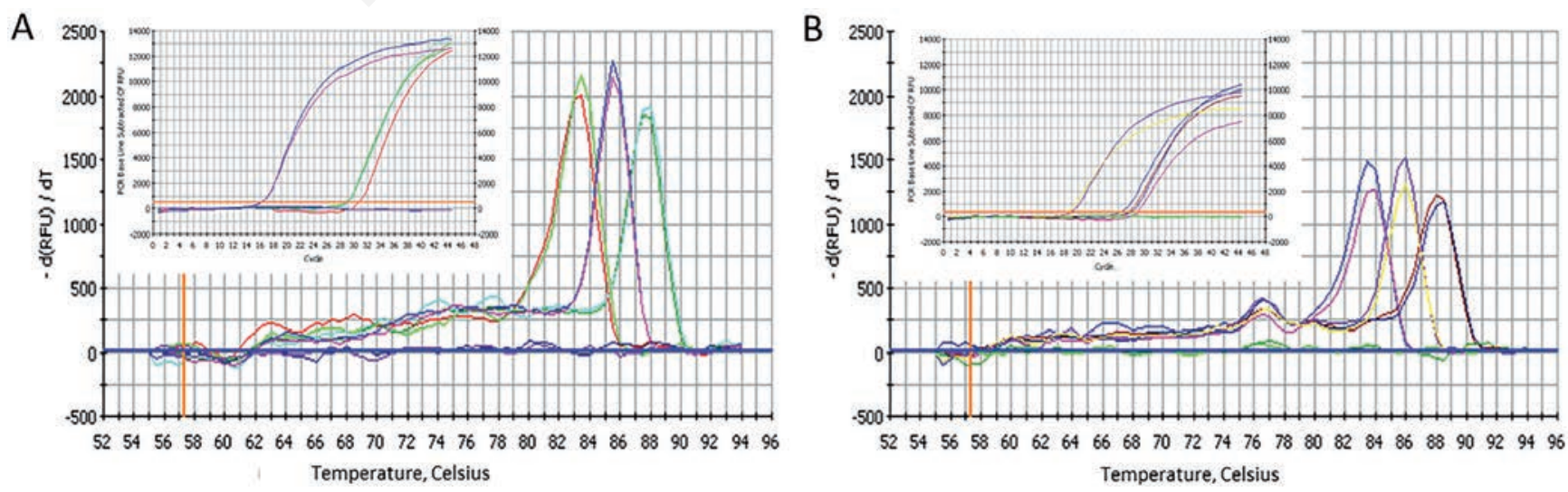

Figure 4. Specific melting point plots of the PCR products using primers for S18, CB1 receptor and CB2 receptor on fibroblasts derived from human fascia (A) and on hip fascial tissue (B). The violet (A) and the green (B) curves are the results about water. On the insets the real time PCR plots with cDNA. 
(eCBs) and the expression of genes coding for CB1 and CB2. Besides, it is known that the connective tissue is one of the principal target of the stretching, causing the remodeling of the cytoskeleton of the fibroblast ${ }^{29}$ and a modulation of the inflammation-regulation mechanisms within connective tissue. ${ }^{30}$ Consequently, we can suppose that specific exercises or fascial treatments could be able to stimulate the fascial fibroblasts and consequently to modulate the endocannabinoid system and the release of anti-inflammatory cytokines. A better comprehension of the interactions between fibroblasts, extracellular matrix and CB1 and CB2 receptors could help to better target the treatments for the myofascial pain.

\section{References}

1. Pavan PG, Stecco A, Stern R, Stecco C. Painful connections: densification versus fibrosis of fascia. Curr Pain Headache Rep 2014;18:441.

2. Schleip R, Naylor IL, Ursu D, Melzer W, Zorn A, Wilke HJ, et al. Passive muscle stiffness may be influenced by active contractility of intramuscular connective tissue. Med Hypotheses 2006;66:66-71.

3. Goldman N, Chandler-Militello D, Langevin HM, Nedergaard M, Takano T. Purine receptor mediated actin cytoskeleton remodeling of human fibroblasts. Cell Calcium 2013;53:297-301.

4. McPartland JM1, Giuffrida A, King J, Skinner E, Scotter J, Musty RE. Cannabimimetic effects of osteopathic manipulative treatment. J Am 0steopath Assoc 2005;105:283-91.

5. Bonz A, Laser M, Küllmer S, Kniesch S, Babin-Ebell J, Popp V et al. Cannabinoids acting onCB1 receptors decrease contractile performance in human atrial muscle. $\mathrm{J}$ Cardiovasc Pharmacol 2003;41:657-64.

6. Bátkai S, Pacher P, Osei-Hyiaman D, Radaeva S, Liu J, Harvey-White J et al. Endocannabinoids acting at cannabinoid-1 receptors regulate cardiovascular function in hypertension. Circulation 2004;110:1996-2002.

7. Mukhopadhyay P, Bátkai S, Rajesh M, Czifra N, Harvey-White J, Haskó G et al. Pharmacological inhibition of CB1 cannabinoid receptor protects against doxorubicin-induced cardiotoxicity. J Am Coll Cardiol 2007;50:528-36.

8. Pacher P, Batkai S, Kunos G. The endocannabinoid system as an emerging target of pharmacotherapy. Pharmacol Rev 2006;58:389-462.

9. Howlett AC. Cannabinoid receptor signaling. Handb Exp Pharmacol 2005;168:53-79.

10. Matias I, Bisogno T, Di Marzo V. Endogenous cannabinoids in the brain and peripheral tissues: regulation of their levels and control of food intake. Int $\mathrm{J}$ Obes 2006;30:S7-12.

11. Rajesh M, Mukhopadhyay P, Bátkai S, Haskó G, Liaudet L, Huffman JW et al. CB2-receptor stimulation attenuates TNFalpha-induced human endothelial cell activation, transendothelial migration of monocytes, and monocyte-endothelial adhesion. Am J Physiol Heart Circ Physiol 2007;293:H2210-8.

12. Rajesh M, Mukhopadhyay P, Haskó G, Huffman JW, Mackie K, Pacher P. CB(2) cannabinoid receptor agonists attenuate TNF-alpha-induced human vascular smooth muscle cell proliferation and migration. $\mathrm{Br}$ J Pharmacol 2008;153:347-37.

13. Van Sickle MD, Duncan M, Kingsley PJ, Mouihate A, Urbani P, Mackie $\mathrm{K}$ et al. Identification and functional characterization of brainstem cannabinoid CB2 receptors. Science 2005;310:329-32.

14. Mallat A, Lotersztajn S. Endocannabinoids and liver disease. I. Endocannabinoids and their receptors in the liver. Am J Physiol Gastrointest Liver Physiol 2008;294:G9-12.

15. Pacher P, Gao B. Endocannabinoid effects on immune cells: implications for inflammatory liver diseases. Am J Physiol Gastrointest Liver Physiol 2008;294:G850-4.

16. Galiègue S, Mary $S$, Marchand $J$, Dussossoy D, Carrière $\mathrm{D}$, Carayon $\mathrm{P}$, et al. Expression of central and peripheral cannabinoid receptors in human immune tissues and leukocyte subpopulations. Eur J Biochem 1995;232:54-61.

17. Ständer S, Schmelz M, Metze D, Luger T, Rukwied R. Distribution of cannabinoid receptor 1 (CB1) and 2 (CB2) on sensory nerve fibers and adnexal structures in human skin. J Dermatol Sci 2005;38:177-88.

18. Garcia-Gonzalez E, Selvi E, Balistreri E, Lorenzini S, Maggio R, Natale MR, et al. Cannabinoids inhibit fibrogenesis in diffuse systemic sclerosis fibroblasts. Rheumatology 2009;48:1050-6.

19. Pandey R, Mousawy K, Nagarkatti M, Nagarkatti P. Endocannabinoids and immune regulation. Pharmacol Res 2009; 60:85-92.

20. Lowin T, Zhu W, Dettmer-Wilde K, Straub RH. Cortisol-mediated adhesion of synovial fibroblasts is dependent on the degradation of anandamide and activation of the endocannabinoid system. Arthritis Rheum 2012;64:3867-76.

21. Russo EB. Clinical endocannabinoid deficiency (CECD): can this concept explain therapeutic benefits of cannabis in migraine, fibromyalgia, irritable bowel syndrome and other treatment-resistant conditions? Neuro Endocrinol Lett 2004; 25:31-9.

22. Fiz J, Durán M, Capellà D, Carbonell J, Farré M. Cannabis use in patients with fibromyalgia: effect on symptoms relief and health-related quality of life. PLoS One 2011;6:e18440.

23. Albertin G, Carraro G, Nussdorfer GG. Human adrenomedullin gene silencing by short interfering RNAs: a preliminary study. Int J Mol Med 2005;15:579-83.

24. Albertin G, Rucinski M, Carraro G, Forneris M, Andreis PG, Malendowicz LK, et al. Adrenomedullin and vascular endothelium growth factor genes are overexpressed in the regenerating rat adrenal cortex, and AM and VEGF reciprocally enhance their mRNA expression in cultured rat adrenocortical cells. Int $\mathrm{J}$ Mol Med 2005;16:431-5.

25. Kumka M, Bonar J. Fascia: morphological description and classification system based on a literature review. J Can Chiropr Assoc 2012;56:179-91.

26. Thellin 0, Zorzi W, Lakaye B, De Borman B, Coumans B, Hennen G et al. Housekeeping genes as internal standards: use and limits. J Biotechnol 1999; 75:291-5.

27. Aggarwal SK, Carter GT, Sullivan MD, ZumBrunnen C, Morrill R, Mayer JD. Characteristics of patients with chronic pain accessing treatment with medical cannabis in Washington State. J Opioid Manag 2009:5:257-86.

28. Gamelin FX, Aucouturier J, Iannotti FA, Piscitelli F, Mazzarella E, Aveta T, et al. Effects of chronic exercise on the endocannabinoid system in Wistar rats with high-fat diet-induced obesity. J Physiol Biochem 2016;1-17.

29. Langevin HM, Nedergaard M, Howe AK. Cellular control of connective tissue matrix tension. J Cell Biochem 2013;114: 1714-9.

30. Berrueta L, Muskaj I, Olenich S, Butler T, Badger GJ, Colas RA et al. Stretching impacts inflammation resolution in connective tissue. J Cell Physiol 2016;2317: 1621-7. 